\title{
Phosphoinositide-3-kinase inhibition induces sodium/iodide symporter expression in rat thyroid cells and human papillary thyroid cancer cells
}

\author{
Takahiko Kogai ${ }^{1}$, Saima Sajid-Crockett ${ }^{1}$, Lynell S Newmarch ${ }^{1}$, Yan-Yun Liu ${ }^{1}$ and Gregory A Brent ${ }^{1,2}$ \\ Departments of ${ }^{1}$ Medicine and ${ }^{2}$ Physiology, David Geffen School of Medicine at UCLA, Endocrinology and Diabetes Division, VA Greater Los Angeles \\ Healthcare System, 11301 Wilshire Boulevard, Building 114, Room 230, Los Angeles, California 90073, USA \\ (Correspondence should be addressed to T Kogai; Email: tkogai@ucla.edu)
}

\begin{abstract}
TSH stimulation of sodium iodide symporter (NIS) expression in thyroid cancer promotes radioiodine uptake and is required to deliver an effective treatment dose. Activation of the insulin/phosphoinositide-3-kinase (PI3K) signaling pathway in TSH-stimulated thyroid cells reduces NIS expression at the transcriptional level. We, therefore, investigated the effects of PI3K pathway inhibition on iodide uptake and NIS expression in rat thyroid cell lines and human papillary thyroid cancer cells. A PI3K inhibitor, LY294002, significantly enhanced iodide uptake in two rat thyroid cell lines, FRTL- 5 and PCCL3. The induction of Nis mRNA by LY294002 occurred $6 \mathrm{~h}$ after treatment, and was abolished by a translation inhibitor, cycloheximide. Expression of the transcription factor, Pax8, which stimulates NIS expression, was significantly increased in PCCL3 cells after LY294002 treatment. Removal of insulin abrogated the stimulatory
\end{abstract}

effects of LY294002 on NIS mRNA and protein expression, but not on iodide uptake. These findings suggest that PI3K pathway inhibition results in post-translational stimulation of NIS. Inhibition of the PI3K pathway also significantly increased iodide uptake $(\sim 3.5$-fold $)$ in BHP $2-7$ papillary thyroid cancer cells (Ret/PTC1 positive), engineered to constitutively express NIS. Pharmacological inhibition of Akt, a factor stimulated by the PI3K pathway, increased exogenous NIS expression in BHP $2-7$ as was seen with LY294002, but not increase the endogenous NIS expression in FRTL-5 cells. PI3K pathway inhibition increases functional NIS expression in rat thyroid cells and some papillary thyroid cancer cells by several mechanisms. PI3K inhibitors have the potential to increase radioiodide accumulation in some differentiated thyroid cancer.

Journal of Endocrinology (2008) 199, 243-252

\section{Introduction}

The $\beta$-emitting isotope, radioiodide-131 ( $\left.{ }^{131} \mathrm{I}\right)$, is commonly used in the treatment of differentiated thyroid cancer after thyroidectomy. The sodium/iodide symporter (NIS), expressed in more than $70 \%$ of differentiated thyroid cancer, mediates ${ }^{131} \mathrm{I}$ accumulation. Functional NIS expression, however, is reduced in tumor tissue compared with the normal thyroid gland, as evidenced by the usual finding of a 'cold' area, which does not concentrate iodide on a standard radioiodine scan. Reduced NIS mRNA expression, as well as reduced NIS trafficking to the plasma membrane, has been reported in differentiated thyroid cancer (Kogai et al. 2006).

TSH induces NIS expression in thyroid follicular cells (Kogai et al. 1997, Saito et al. 1997) and differentiated thyroid cancer cells (Saito et al. 1998). The thyrotrophin (TSH) signaling pathways upregulate NIS expression in thyroid cells at the transcriptional and post-transcriptional levels (Kogai et al. 1997, Riedel et al. 2001, Taki et al. 2002). TSH receptor activation stimulates adenylyl cyclase through the stimulatory $\mathrm{G} \alpha$ protein, followed by intracellular cAMP accumulation. The TSH/cAMP pathway stimulates the NIS proximal promoter (Endo et al. 1997,

Ohmori et al. 1998) and the NIS upstream enhancer (NUE; Ohno et al. 1999, Taki et al. 2002), stabilizes the NIS protein, and stimulates trafficking of NIS to the cell surface membrane (Riedel et al. 2001). ${ }^{131}$ I uptake in thyroid cancer is enhanced by an increase in endogenous TSH, accomplished by cessation of thyroid hormone supplementation in athyreotic patients postthyroidectomy, or administration of recombinant TSH.

Expression of NIS alone in mammalian cells enables them to accumulate iodide (Kosugi et al. 1996, Saito et al. 1997, Shimura et al. 1997, Kogai et al. 2001). Nis mRNA expression level is correlated with iodide uptake in TSH-stimulated FRTL-5 cells (Kogai et al. 1997). Abundant expression of NIS mRNA and protein, however, do not always confer increased iodide uptake in thyroid cancer tissues, likely due to the failure of NIS translocation to the membrane (Dohan et al. 2001, Riesco-Eizaguirre et al. 2006).

Insulin, as well as insulin-like growth factor-I (IGF-I), reduces TSH-induced iodide uptake in FRTL-5 rat thyroid cells (Saji \& Kohn 1991). Phosphoinositide-3-kinase (PI3K) is one of the major mediators of insulin/IGF signaling. Selective inhibitors of PI3K, such as LY294002 and Wortmannin, significantly increase Nis mRNA expression in rat thyroid 
cells by stimulating its transcription (Garcia \& Santisteban 2002, Giuliani et al. 2007). Although enhancement of iodide uptake with LY294002 has been incidentally observed in TSH-stimulated FRTL-5 cells (Kogai et al. 2008), the effects of PI3K inhibition on the iodide uptake in thyroid cells have not been well characterized.

Optimizing iodide uptake and prolonging the period of radioiodine tumor residence are important for effective ${ }^{131} \mathrm{I}$ treatment of thyroid cancer. We, therefore, investigated the effects of PI3K inhibitors on iodide uptake and efflux, as well as NIS expression, in papillary thyroid cancer cells. We further investigated whether PI3K inhibition influences the posttranscriptional regulation of NIS by using papillary thyroid cancer cells and anaplastic thyroid cancer cells engineered to constitutively express NIS. The in vitro response of NIS to stimulators, such as TSH and retinoic acid, often differs between normal thyroid cells and thyroid cancer cell lines (Schmutzler et al. 1997, Kogai et al. 2001). We, therefore, compared the response in thyroid cancer cells to that in FRTL-5 and PCCL3 rat thyroid cells.

\section{Materials and Methods}

\section{Cell culture}

FRTL-5 cells (a fresh sub-clone F1, passage number 6-12) were maintained in Coon's modified Ham's F-12 medium (Sigma) supplemented with 5\% calf serum (Invitrogen) and a sixhormone $(6 \mathrm{H})$ mixture containing bovine insulin $(10 \mu \mathrm{g} / \mathrm{ml})$, hydrocortisone $(1 \mathrm{nM})$, transferrin $(5 \mu \mathrm{g} / \mathrm{ml})$, L-glycyl-histidyllysine $(10 \mathrm{ng} / \mathrm{ml})$, somatostatin $(10 \mathrm{ng} / \mathrm{ml})$, and bovine $\mathrm{TSH}$ ( $1 \mathrm{mU} / \mathrm{ml} ; 6 \mathrm{H} 5 \%$ medium), as previously described (Kogai et al. 1997). PCCL3 cells (passage number 8-11) were also maintained in the $6 \mathrm{H} 5 \%$ medium. To study the effects of TSH, forskolin (FSK), and/or inhibitors, 50-60\% confluent cells were pre-treated without TSH in the presence of $5 \%$ calf serum (5H5\% medium) for 7 days. To study the effects of FSK, insulin, and/or inhibitors in FRTL-5 cells, cells were pre-treated in the $5 \mathrm{H} 5 \%$ medium for 5 days, followed by $4 \mathrm{H}$ medium (without TSH or insulin) with reduced serum $(0 \cdot 2 \% ; 4 \mathrm{H} 0 \cdot 2 \%$ medium $)$ for 2 days. Thyroid cancer cells, BHP 2-7 cells, NPA cells, and ARO cells, were maintained in RPMI1640 medium (Sigma) with 10\% fetal bovine serum (Invitrogen), as described (Kogai et al. 2001). To study the effects of insulin, FSK, and/or inhibitors in thyroid cancer cells, 40-50\% confluent cells were pre-treated in the $4 \mathrm{H} 0 \cdot 2 \%$ medium for 2 days.

\section{Chemicals}

Signal transduction inhibitors, purchased from EMD Biosciences (La Jolla, CA, USA), were aliquoted in dimethyl sulfoxide (DMSO) at $30 \mathrm{mM}$ (or $1 \mathrm{mM}$ for Wortmannin), stored at $-20^{\circ} \mathrm{C}$, and used within 2 months. Bovine TSH, bovine insulin, and other chemicals were purchased from Sigma, unless otherwise noted.
Iodide uptake assay

Iodide uptake assay was performed with $20 \mathrm{mCi} / \mathrm{mmol} \mathrm{Na}^{125} \mathrm{I}$, as described (Kogai et al. 2005), with minor modifications. Briefly, cells grown in 12-well dishes were incubated for $1 \mathrm{~h}$ at $37^{\circ} \mathrm{C}$ with $500 \mu \mathrm{l}$ Hank's balanced salt solution (HBSS) containing $\sim 0 \cdot 1 \mu \mathrm{Ci}$ carrier-free $\mathrm{Na}^{125} \mathrm{I}$ (GE Healthcare, Piscataway, NJ, USA) and $10 \mu \mathrm{M} \mathrm{NaI}$. After the incubation, the cells were washed twice with ice-cold HBSS, scraped from each well, and radioactivity measured in a $\gamma$-counter. Cell number was determined by counting in a hemocytometer. The radioactivity was normalized to the cell number at the time of the assay. For cells transiently expressing NIS, cells were lysed with $200 \mu$ passive lysis buffer (Promega) after the incubation with $\mathrm{Na}^{125}$ I. Radioactivity of the cell lysates was measured in a $\gamma$-counter, and normalized with Renilla luciferase (RLuc) activity derived from a co-transfected RLuc reporter vector, pRL-CMV (Promega).

\section{Iodide efflux assay}

The procedure was performed as has been described previously (Kogai et al. 2000). Briefly, cells in 12-well dishes were incubated with HBSS containing $10 \mu \mathrm{M} \mathrm{NaI}$ and $20 \mathrm{mCi} / \mathrm{mmol} \mathrm{Na}{ }^{125} \mathrm{I}$ for $1 \mathrm{~h}$, and the medium was replaced every $5 \mathrm{~min}$ with fresh HBSS without $\mathrm{NaI}$. The content of ${ }^{125} \mathrm{I}$ in the collected supernatant was measured by $\gamma$-counter. After the last time point $(60 \mathrm{~min})$, the cells were extracted with $400 \mu$ l ethanol to count residual radioactivity.

\section{Reverse transcription and quantitative real-time PCR (RT-qPCR) analysis}

Two-step quantitative RT-PCR was carried out, as described (Kogai et al. 2005), with minor modifications. Briefly, total RNA was isolated by RNeasy mini kit (Qiagen) from cells grown in six-well plates. On-column DNase I digestion was performed as recommended by Qiagen. Three micrograms of purified total RNA were reverse-transcribed by using 50 units of Superscript III reverse transcriptase (Invitrogen) with oligo(dT) ${ }_{12-18}$ primer $(1 \mu \mathrm{g})$. Quantitative PCR of human NIS and human GAPDH was performed with DNA Engene Opticon System (MJ Research, Waltham, MA, USA), as described (Kogai et al. 2005). PCR of rat Nis and rat Gapdh was performed with the following primers; rat Nis forward, GATGTGTTCCAGGTTGTGGTAATG; rat Nis reverse, CAGGGTCAAAGTCCACTAGGTT; rat Gapdh forward, AGTCAAGGCTGAGAATGGGAAG; rat Gapdh reverse, GGTGGTGAAGACGCCAGTAGA. Cycle parameters for rat Nis and Gapdh were the same as that for human NIS (Kogai et al. 2005). PCR of rat Pax 8 was performed with QuantiTect Primer Assay (Qiagen), as recommended. Standard curves representing six-point serial dilution of mixed cDNA of the control group, BHP 2-7 cells constitutively expressing NIS for human NIS and GAPDH, or FRTL-5 cells maintained in the $6 \mathrm{H} 5 \%$ medium for rat Nis and Gapdh, were analyzed in each 
assay and used for calculation of relative expression values. The sample quantifications of NIS mRNA were normalized by the internal control GAPDH mRNA.

\section{Transfection}

A human NIS expression vector, pcDNA3-human NIS cDNA (Saito et al. 1997), was transfected to thyroid cancer cells with Nucleofector system (Amaxa, Gaithersburg, MD, USA). For transient expression study, pRL-CMV was co-transfected, and RLuc assay was performed with a commercial kit (Promega). For stable expression, the transfected cells were selected with G418 (Invitrogen) for 3-4 weeks. Constitutive expression of exogenous gene was confirmed with RT-qPCR.

\section{Western blot analysis}

Whole cell lysates were prepared in $10 \mathrm{mM}$ Hepes-KOH $(\mathrm{pH}$ 7.5) and $1 \mathrm{mM}$ EGTA with a protease inhibitor cocktail (Sigma), and quantified with the Bio-Rad Protein Assay. Thirty micrograms of protein were denatured with $2 \%$ SDS and $50 \mathrm{mM}$ dithiothreitol, loaded on a SDS-PAGE $(7 \cdot 5 \%)$, transferred to a polyvinylidene fluoride (PVDF) membrane (Millipore, Billerica, MA, USA), and immunoblotted with anti-rat NIS antibody (generously provided by Dr Nancy Carrasco, Albert Einstein College of Medicine, Bronx, NY, USA) at 1:3000. The filter membrane was stripped with restore western blot stripping buffer (Pierce Biotechnology, Rockford, IL, USA) and reprobed with anti- $\beta$ actin antibody (Cell Signaling Technology, Danvers, MA, USA) at 1:2000. Blots were exposed to X-ray films, and intensities of signals were scanned and quantitated by using the Image J program version 1.40 (Abramoff et al. 2004).

\section{Statistical analysis}

Statistical comparison was performed using StatView 5.0 software (Abacus Concept, Berkeley, CA, USA) with significance at $P<0 \cdot 05$. Comparison between groups was determined by conducting a paired Student's $t$-test.

\section{Results}

Effects of PI3K pathway inhibition by LY294002 on iodide uptake in rat thyroid cells

To study the effects of PI3K inhibition on iodide uptake in thyroid cells, we treated TSH/cAMP-stimulated FRTL-5 cells with a PI3K inhibitor (LY294002). The cells, maintained in the $5 \mathrm{H} 5 \%$ medium (in the presence of $5 \%$ serum but without TSH) for 7 days, were treated for $48 \mathrm{~h}$ with or without LY294002, TSH, and/or an adenylyl cyclase stimulator FSK. PI3K inhibition (LY294002, $30 \mu \mathrm{M})$ significantly increased the iodide uptake in TSH-stimulated FRTL-5 cells $(\sim 1 \cdot 9$-fold), as well as FSK-stimulated cells $(\sim 1 \cdot 8$-fold; Fig. 1A).
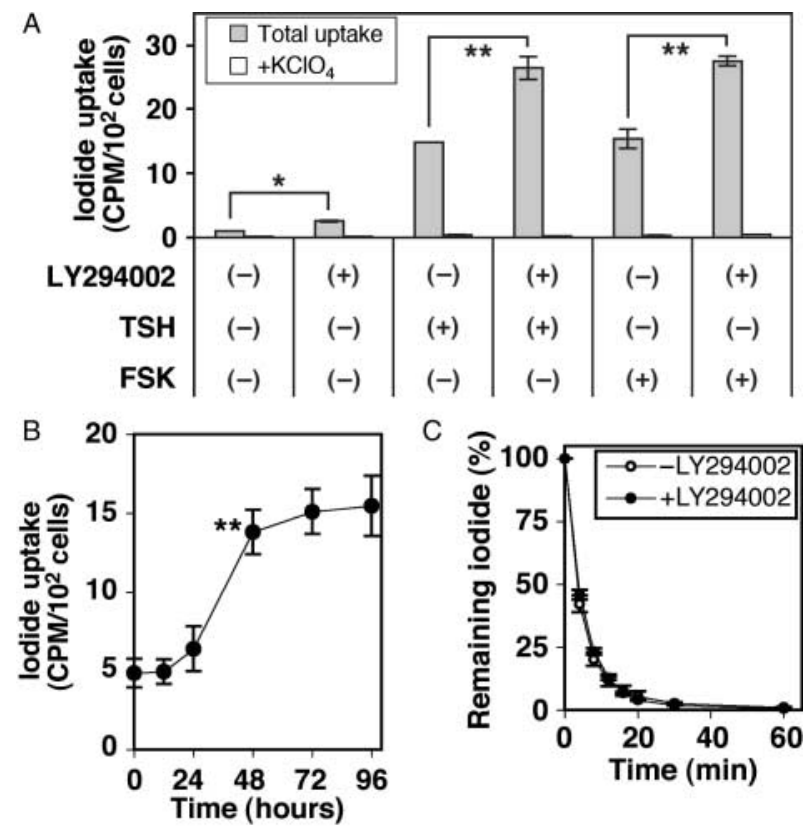

Figure 1 Effects of PI3K inhibition by LY294002 on iodide uptake in FRTL- 5 cells. (A) Cells maintained in the $5 \mathrm{H} 5 \%$ medium (without TSH) for 7 days were treated with $1 \mathrm{mU} / \mathrm{ml}$ bovine TSH, $10 \mu \mathrm{M} \mathrm{FSK}$, and/or $30 \mu \mathrm{M} \mathrm{LY} 294002$ for $48 \mathrm{~h}$, and iodide uptake assay was performed with ${ }^{125} \mathrm{I}(20 \mathrm{mCi} / \mathrm{mmol})$ and $10 \mu \mathrm{M} \mathrm{Nal}$. Non-specific uptake of iodide was measured with $30 \mu \mathrm{M}$ of $\mathrm{KClO}_{4}$, the specific inhibitor of $\mathrm{NIS}$, in duplicate wells. Values are expressed as means \pm s.D. $(n=3)$. $* P<0 \cdot 02 ; * * P<0 \cdot 01$. (B) Time course of induction of iodide uptake by LY294002 in FRTL-5 cells. Cells continuously maintained in the $6 \mathrm{H} 5 \%$ medium (with $1 \mathrm{mU} / \mathrm{ml}$ of TSH) were treated with $30 \mu \mathrm{M}$ of LY294002 for the indicated time, and iodide uptake assay was performed. Values are expressed as means \pm s.D. $(n=3) .{ }^{* *} P<0 \cdot 01$, when compared with the cells before the treatment $(0 \mathrm{~h})$. (C) lodide efflux in FRTL-5 cells treated with or without LY294002. Cells, continuously maintained in the $6 \mathrm{H} 5 \%$ medium, were treated with $30 \mu \mathrm{M}$ of LY294002 for $48 \mathrm{~h}$, and iodide efflux assay was performed. Values are expressed as means \pm s.D. $(n=3)$.

A specific inhibitor of NIS-mediated iodide uptake, $\mathrm{KClO}_{4}$, abolished the uptake induced by TSH, FSK, and/or LY294002 (Fig. 1A), indicating that the increased iodide uptake is mediated by NIS. Since non-specific iodide accumulation in the presence of $\mathrm{KClO}_{4}$ was not significantly changed with LY294002, the induction of iodide uptake by PI3K pathway inhibition may be dependent on the induction of functional NIS expression.

Modulation of the TSH/Gßr signaling by LY294002 has been proposed as the mechanism for NIS induction (Zaballos et al. 2008). LY294002 treatment, however, significantly increased iodide uptake $(\sim 2 \cdot 5$-fold), even in the absence of TSH stimulation (Fig. 1A). Significant induction of iodide uptake $(\sim 2 \cdot 8$-fold $)$ was also observed in FRTL-5 cells continuously treated with the $6 \mathrm{H} 5 \%$ medium (Fig. 1B), in which the cells were chronically stimulated by TSH. These data indicate that the induction of iodide uptake by PI3K pathway inhibition (LY294002) is demonstrated in the presence and absence of TSH/cAMP pathway activation. 
A time course study of the induction of iodide uptake by PI3K inhibition (LY294002) in FRTL-5 cells maintained in the $6 \mathrm{H} 5 \%$ medium was performed. Significant induction of iodide uptake was seen at $48 \mathrm{~h}$ and reached a maximum at $72 \mathrm{~h}$ (Fig. 1B). The stimulation of iodide uptake was also observed in another rat thyroid cell line, PCCL3, maintained with $6 \mathrm{H} 5 \%$ media (data not shown).

An increase in the net iodide uptake is predominantly the result of an increase in iodide influx, but is also influenced by iodide efflux. We, therefore, measured iodide efflux in FRTL5 cells treated with PI3K pathway inhibition (LY294002) and TSH for $48 \mathrm{~h}$, and compared with cells treated with TSH alone. The time point at which $50 \%$ of iodide remained in the TSH-stimulated cells was $\sim 3.4$ min (Fig. 1C), consistent with previous data (Kogai et al. 2000). PI3K pathway inhibition (LY294002) did not significantly influence this time point $(\sim 3.8 \mathrm{~min} ;$ Fig. $1 \mathrm{C})$. These data indicate that PI3K pathway inhibition (LY294002) in FRTL5 cells increases iodide uptake by increasing influx mediated by NIS, but does not influence efflux.

\section{Effects of PI3K pathway inhibition by LY294002 on Nis} $m R N A$ expression in rat thyroid cells

TSH induces iodide uptake in TSH-starved FRTL-5 cells 12-24 h after the initiation of treatment (Kogai et al. 1997). Since the induction of Nis mRNA by TSH is relatively rapid (within $6 \mathrm{~h}$ ), the delayed induction of iodide uptake has been thought to involve post-transcriptional regulation (Kogai et al. 1997, Riedel et al. 2001). The stimulatory effect of PI3K inhibition (LY294002) on iodide uptake was not seen until $48 \mathrm{~h}$ (Fig. 1B). We therefore performed a time course study of Nis mRNA induction by LY294002 in FRTL-5 cells. In contrast with the rapid effect of TSH on Nis mRNA stimulation, significant induction of Nis mRNA by LY294002 was observed in cells continuously maintained with TSH (6H5\% medium) at $24 \mathrm{~h}$ (Fig. 2A). The translation inhibitor, cycloheximide, abolished the LY294002-induced Nis mRNA expression (Fig. 2B). The delayed induction of Nis mRNA by LY294002, therefore, is likely due to de novo protein synthesis for the NIS induction.

\section{Effects of PI3K pathway inhibition by LY294002 on Pax8 expression in rat thyroid cells}

NIS expression is transcriptionally regulated by TSH/cAMP signaling through a thyroid-specific NIS upstream enhancer, NUE (Ohno et al. 1999, Taki et al. 2002). The NUE recruits a paired domain-containing transcription factor PAX8, and cAMP-response element-binding proteins, in response to the TSH/cAMP signal (Taki et al. 2002). PI3K inhibition by LY294002 increases the binding of PAX8 to the NUE in PCCL3 rat thyroid cells (Zaballos et al. 2008). Since the NIS mRNA induction by LY294002 likely requires newly synthesized protein, we hypothesized that the induction of Pax 8 is required for the full induction of NIS. We therefore
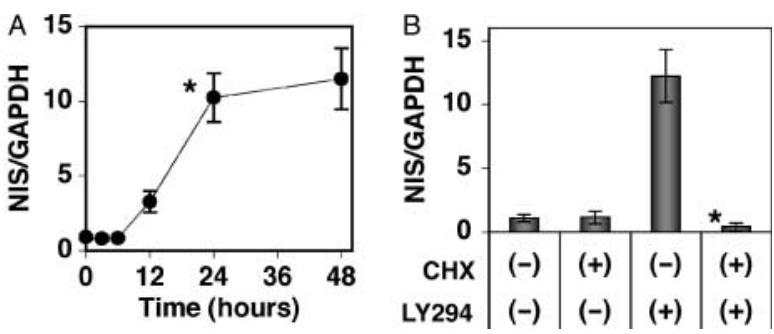

Figure 2 Induction of Nis mRNA after PI3K inhibition by LY294002 in FRTL-5 cells. (A) Time course of induction of Nis mRNA by LY294002. Cells continuously maintained in the $6 \mathrm{H} 5 \%$ medium were treated with $30 \mu \mathrm{M}$ LY294002 for the indicated time, and RT-qPCR of Nis was performed. Values are expressed as means \pm S.D. $(n=3) .{ }^{*} P<0 \cdot 01$, when compared with the cells before the treatment $(0 \mathrm{~h})$. (B) Effect of cycloheximide on the Nis mRNA expression in FRTL-5 cells. Cells continuously maintained in the $6 \mathrm{H} 5 \%$ medium were treated with $5 \mu \mathrm{g} / \mathrm{ml}$ cycloheximide (CHX) and/or $30 \mu \mathrm{M}$ LY294002 (LY294) for $24 \mathrm{~h}$, and RT-qPCR of Nis was performed. Values are expressed as means \pm s.D. $(n=4)$. ${ }^{*} P<0 \cdot 01$, when compared with the cells treated with only LY294002.

performed RT-qPCR of Pax8 in FRTL-5 cells as well as PCCL3 cells, both of which were treated with LY294002 for 24 h. PI3K inhibition by LY294002 significantly increased the Pax 8 mRNA expression in PCCL3 cells $(3 \cdot 26$-fold, Table 1), consistent with the upregulation of NUE with Pax8 previously reported in these cells (Zaballos et al. 2008). Unexpectedly, LY294002 did not significantly induce the Pax 8 mRNA in FRTL-5 cells (Table 1), suggesting induction of other protein(s) required for the full induction of Nis after PI3K inhibition by LY294002 in FRTL-5 cells. Comparison of Nis mRNA expression in both cell lines induced in response to PI3K inhibition (Table 1) indicate that the magnitude of Nis induction in PCCL3 $(\sim 9 \cdot 0$-fold $)$ was significantly greater than that in FRTL-5 cells $(\sim 6 \cdot 8$-fold). The Pax 8 induction by LY294002 may produce an additive effect on the NIS induction in PCCL3 cells.

Comparison of effects of various PI3K inhibitors on iodide uptake and Nis $m R N A$ expression in rat thyroid cells

LY294002 is a potent selective inhibitor of PI3K with broad spectrum for PI3K isoforms. LY294002, however, also interacts many cellular proteins and inhibits some other kinases, such as casein kinase II, Pim-1 kinase, glycogen synthase kinase 3 , and the $97 \mathrm{kDa}$ valosin-containing protein (Gharbi et al. 2007). To investigate whether the effect of LY294002 on iodide uptake is dependent on PI3K inhibition, we characterized the effect of LY294002 on iodide uptake in FRTL-5 cell compared with LY303511, an inactive analogue of LY294002, as well as another pan-PI3K inhibitor Wortmannin and a class 1 PI3K p110 $\alpha$ (PI3KCA)-selective inhibitor PI-103 (Knight et al. 2006). The effect of LY294002 on the iodide uptake stimulated by TSH was concentrationdependent with an $\mathrm{EC}_{50}$ of $3.57 \mu \mathrm{M}$ (Fig. 3A), in the range of previously reported values for in vivo inhibition of PI3K (El-Kholy et al. 2003). The $\mathrm{EC}_{50}$ for iodide uptake in PCCL3 
Table 1 Differential effects of PI3K inhibition by LY294002 on Nis mRNA and Pax8 mRNA expression in FRTL-5 cells and PCCL3 cells. Cells were pre-treated with the $5 \mathrm{H} 5 \%$ medium for 7 days, and stimulated with $10 \mu \mathrm{M}$ of FSK for $24 \mathrm{~h}$ in the presence or absence of LY294002 (30 $\mu \mathrm{M})$

\begin{tabular}{|c|c|c|c|c|c|}
\hline \multirow{2}{*}{\multicolumn{2}{|c|}{$\underline{L Y 294002}$}} & \multicolumn{2}{|l|}{ Nis/Gapdh } & \multicolumn{2}{|l|}{ Pax8/Gapdh } \\
\hline & & Fold induction $^{a}$ & $+\mathrm{LY} /-\mathrm{LY}$ & Fold induction $^{\mathrm{a}}$ & $+\mathrm{LY} /-\mathrm{LY}$ \\
\hline \multirow[t]{2}{*}{ FRTL5 } & - & $23 \cdot 8 \pm 3 \cdot 1$ & & $0 \cdot 33 \pm 0 \cdot 03$ & \\
\hline & + & $160 \cdot 4 \pm 11 \cdot 8$ & $6.75 \pm 1.09$ & $0 \cdot 24 \pm 0.08$ & $0 \cdot 79 \pm 0 \cdot 10$ \\
\hline \multirow[t]{2}{*}{ PCCL3 } & - & $69 \cdot 9 \pm 11 \cdot 8$ & & $0.51 \pm 0.06$ & \\
\hline & + & $629 \cdot 0 \pm 86 \cdot 4$ & $9 \cdot 05 \pm 1 \cdot 65^{*}$ & $1 \cdot 69 \pm 0 \cdot 26$ & $3 \cdot 26 \pm 0 \cdot 27^{\dagger}$ \\
\hline
\end{tabular}

${ }^{*} P<0 \cdot 05 ;{ }^{+} P<0 \cdot 01$, when compared with FRTL-5 cells $(n=6)$.

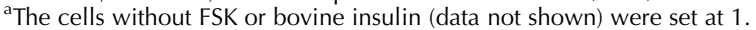

cells was $6.74 \mu \mathrm{M}$, consistent with the range for PI3K inhibition in FRTL-5 cells. The inactive analogue, LY303511, did not significantly influence iodide uptake in FRTL-5 cells (Fig. 3B). Wortmannin, which inhibits PI3K at nano-molar concentrations, enhanced the iodide uptake in a concentration-dependent manner, with an $\mathrm{EC}_{50}$ of $12 \cdot 4 \mathrm{nM}$ (Fig. 3C). Interestingly, the PI3KCA-selective inhibitor, PI-103, did not significantly increase the iodide uptake in FRTL-5 cells (Fig. 3D).

To address the discrepancy between the effects of LY294002 and PI-103 on iodide uptake, we performed RT-qPCR of Nis mRNA in FRTL- 5 cells treated with these inhibitors. Twenty-four hour treatment with TSH significantly increased the Nis mRNA expression in FRTL- 5 cells pretreated in the $5 \mathrm{H} 5 \%$ medium (without TSH) for 5 days (Fig. 4), as reported previously (Kogai et al. 1997). The addition of LY294002, as well as PI-103, significantly enhanced the induction of Nis mRNA $(\sim 8 \cdot 4-$ and $\sim 6 \cdot 2-$ fold respectively; Fig. 4), consistent with the previous observations with LY294002 (Garcia \& Santisteban 2002,
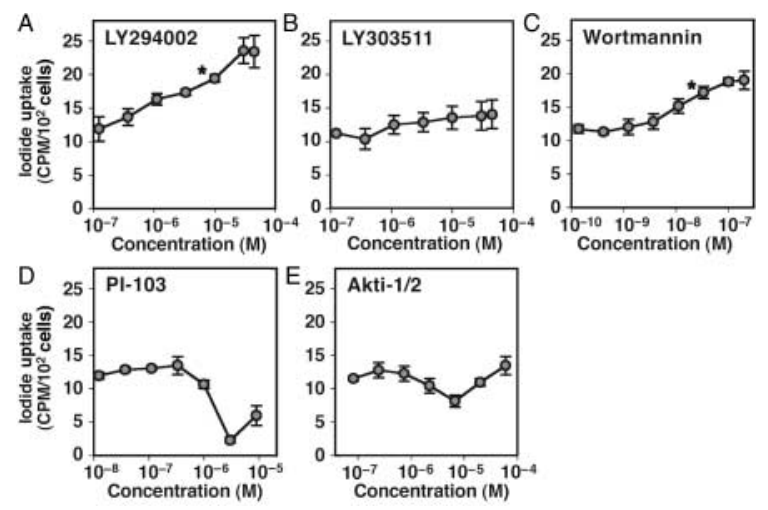

Figure 3 Effects of various inhibitor of PI3K pathway on iodide uptake in FRTL-5 cells. Cells maintained in the $5 \mathrm{H} 5 \%$ medium (without TSH) for 7 days were treated with $1 \mathrm{mU} / \mathrm{ml}$ of bovine TSH and the indicated inhibitor for $48 \mathrm{~h}$ at the indicated concentration. During the treatment, cells were fed with fresh medium and each inhibitor every $24 \mathrm{~h}$. lodide uptake was performed with ${ }^{125}$ I $(20 \mathrm{mCi} / \mathrm{mmol})$ and $10 \mu \mathrm{M} \mathrm{Nal}$. Values are expressed as means \pm S.D. $(n=3) .{ }^{*} P<0 \cdot 01$, when compared with the cells treated with only TSH (not shown).
Giuliani et al. 2007). These data indicate that PI-103 induces the expression of Nis mRNA, but not iodide uptake. PI-103 may inhibit the translation of Nis mRNA or translocation of Nis protein to the plasma membrane.

Although LY294002 possesses an 'off-target' effect on casein kinase II (Gharbi et al. 2007), 4,5,6,7-tetrabromobenzotriazole, a selective casein kinase II inhibitor, did not increase the Nis mRNA in FRTL-5 cells (Fig. 4). The inactive analogue LY303511 also did not significantly affect the Nis mRNA expression in FRTL5 cells (Fig. 4). These observations validate the association of PI3K pathway inhibition and Nis mRNA induction.

PI3K activates its downstream effector, Akt, through phosphatidylinositol (3,4,5)-trisphosphate. Although the PI3K inhibition significantly increased the iodide uptake, an Akt1/Akt2 selective inhibitor, Akti-1/2, did not significantly increase the iodide uptake in FRTL-5 cells in the micromolar range (Fig. 3E). The Akt inhibitor modestly increased the Nis mRNA in TSH-stimulated FRTL-5 cells, but the magnitude was not as significant as that seen with PI3K inhibitors (Fig. 4). These data suggest that unknown downstream effector(s) of PI3K, rather than Akt, are associated with the Nis induction in FRTL-5 cells.

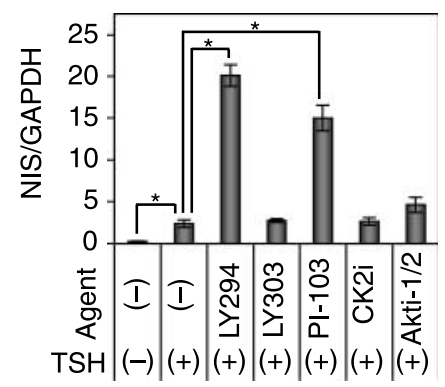

Figure 4 Effects of various kinase inhibitors on Nis mRNA expression in FRTL-5 cells. Cells maintained in the $5 \mathrm{H} 5 \%$ medium (without TSH) for 7 days were treated with or without TSH (1 mU/ml), $30 \mu \mathrm{M}$ LY294002 (LY294), 30 M LY303511 (LY303), $3 \mu \mathrm{M}$ PI-103, $30 \mu \mathrm{M}$ of a casein kinase II inhibitor (CK2i), and/or $30 \mu \mathrm{M}$ of an Akt1/Akt2 selective inhibitor (Akti-1/2), for $24 \mathrm{~h}$, and RT-qPCR of Nis was performed. Values are expressed as means \pm S.D. $(n=3-4) .{ }^{*} P<0 \cdot 01$. 
Requirement of insulin and TSH/cAMP stimulation for the NIS induction by LY294002

The stimulatory effect of PI3K inhibition by LY294002 on Nis mRNA expression is associated with the suppression of insulin signaling (Garcia \& Santisteban 2002). To investigate whether treatment with insulin is necessary for the induction of iodide uptake by LY294002, we evaluated the effects of LY294002 on iodide uptake in serum-deprived FRTL-5 cells. The cells were maintained in the $5 \mathrm{H} 5 \%$ medium (without TSH) for 5 days, the $4 \mathrm{H} 0 \cdot 2 \%$ medium (with $0 \cdot 2 \%$ serum but without $\mathrm{TSH}$ or insulin) for 2 days, and then treated with FSK, insulin, and/or LY294002 for $48 \mathrm{~h}$. The addition of insulin modestly decreased the iodide uptake in the cells without FSK (Fig. 5A; columns 1 and 5). The stimulatory effect of LY294002 was observed both in the presence (Fig. 5A; columns 5 and 6; 7 and 8) and absence (columns 1 and 2; 3 and 4) of insulin. The effects were not dependent on the FSK stimulation, consistent with the data in cells treated with the $5 \mathrm{H} 5 \%$ medium (Fig. 1A). These results indicate that neither insulin nor cAMP stimulation is required for the induction of iodide uptake by PI3K inhibition.
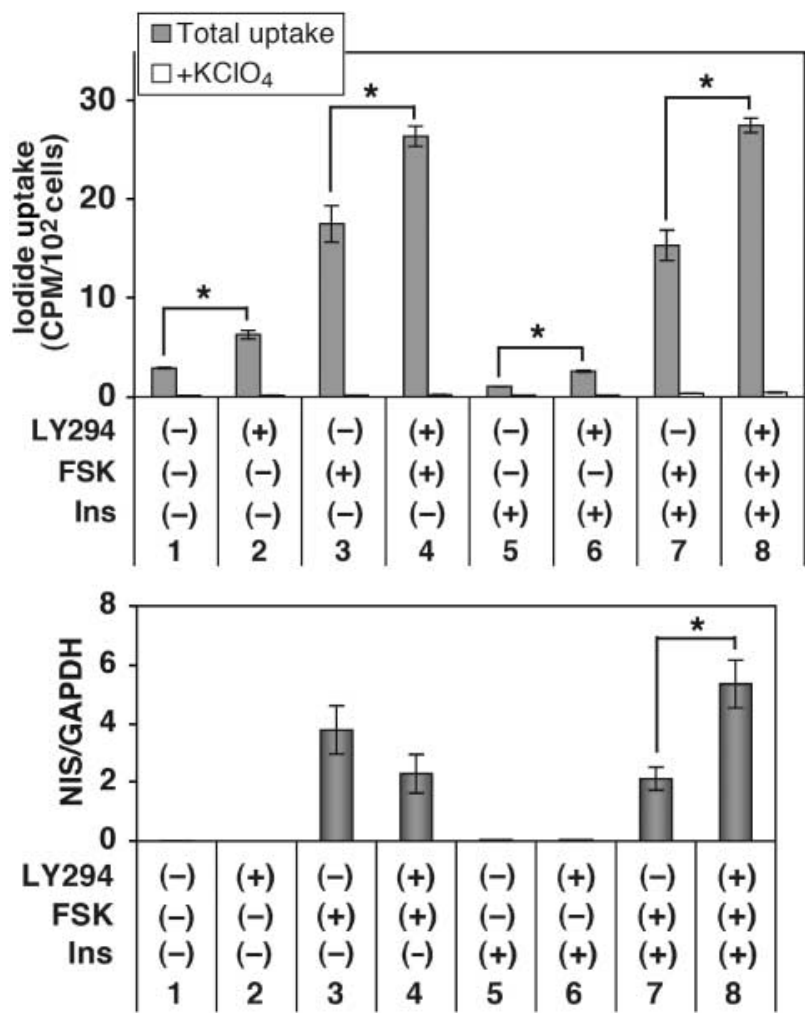

Figure 5 Dependency of the NIS induction by LY294002 on insulin and the CAMP pathway in FRTL-5 cells. Cells were maintained in the $5 \mathrm{H} 5 \%$ medium for 5 days, the $4 \mathrm{H} 0 \cdot 2 \%$ medium for 2 days, and then treated with $30 \mu \mathrm{M}$ of LY294002 (LY294), $10 \mu \mathrm{M}$ of FSK, and/or $10 \mu \mathrm{g} / \mathrm{ml}$ of bovine insulin (Ins) in the $4 \mathrm{HO} \cdot 2 \%$ medium for $48 \mathrm{~h}$ for iodide uptake (A) or for $24 \mathrm{~h}$ for RT-qPCR of Nis (B). Values are expressed as means \pm s.D. $(n=3-4) .{ }^{*} P<0 \cdot 01$.
We also performed RT-qPCR of Nis mRNA with the same batch of FRTL-5 cells pretreated with the $5 \mathrm{H} 5 \%$ medium for 5 days, followed by the $4 \mathrm{HO} \cdot 2 \%$ medium for 2 days. The treatment with LY294002 (24 h) significantly increased the FSK-induced Nis mRNA expression in the presence of insulin ( 2.5-fold; Fig. 5B, columns 7 and 8 ), although the magnitude was smaller than that with $5 \%$ serum $(\sim 6 \cdot 8$-fold; Table 1$)$. In contrast to the induction of iodide uptake, removal of insulin abolished the stimulatory effect of LY294002 on the Nis mRNA expression (Fig. 5B, columns 3 and 4). In the insulin-treated cells, the stimulatory effect of LY294002 was observed in the presence of FSK (Fig. 5B, columns 7 and 8), but not in the absence of FSK (columns 5 and 6). These data indicated that Nis mRNA induction by LY294002 requires both insulin and cAMP pathway stimulation, although the induction of iodide uptake does not require either of those treatments.

The discrepancy in the effects of LY294002 between iodide uptake and Nis mRNA expression in the insulin-deprived FRTL-5 cells suggests a stimulatory effect(s) of the PI3K inhibitor on the NIS protein synthesis and/or its posttranslational regulation. To investigate whether the PI3K inhibition affects the translation of NIS, we performed Western blot analysis of NIS with whole cell lysates from the serumdeprived FRTL-5 cells treated with FSK, insulin, and/or LY294002 for $48 \mathrm{~h}$. The addition of FSK induced the glycosylated NIS, indicated as broad bands (distributed between 65 and $100 \mathrm{kDa}$ ), as well as a non-glycosylated NIS around $50 \mathrm{kDa}$ (Levy et al. 1998), both in the presence and absence of insulin (Fig. 6, lanes 2 and 4). Removal of insulin significantly increased the NIS expression (Fig. 6, lanes 2 and 4), consistent with previous observations (Garcia \& Santisteban 2002). PI3K inhibition by LY294002 significantly increased the expression of glycosylated NIS ( $\sim 2 \cdot 6$-fold), as well as the non-glycosylated NIS, in the presence of insulin (Fig. 6, lanes 4 and 5), but not in the absence of insulin (Fig. 6, lanes 2 and 3). These data indicate that the effects of LY294002 as well as the insulin starvation on the NIS protein expression (Fig. 6) are correlated with those on the Nis mRNA expression in FRTL-5 cells (Fig. 5B). LY294002, therefore, does not likely affect the translation of NIS, but possibly upregulates processing of NIS and/or translocation of NIS to the plasma membrane. In the insulindeprived cells, LY294002 abolished the expression of nonglycosylated NIS (Fig. 6, lane 3). Since the non-glycosylated NIS produces a less iodide uptake (Levy et al. 1998), the inhibition of PI3K may upregulate the NIS by modulating its glycosylation in the insulin-deprived cells.

PI3K inhibition by LY294002 upregulates iodide uptake in Ret-PTC expressing papillary thyroid cancer cells constitutively expressing NIS

We next applied the PI3K inhibitor to two papillary thyroid cancer cell lines, BHP 2-7, RET/PTC1-expressing cells (Vitagliano et al. 2004) and NPA, BRAF mutant (V600E)expressing cells. Although the $24 \mathrm{~h}$ treatment with FSK, as well as LY294002, tended to increase the endogenous NIS mRNA 


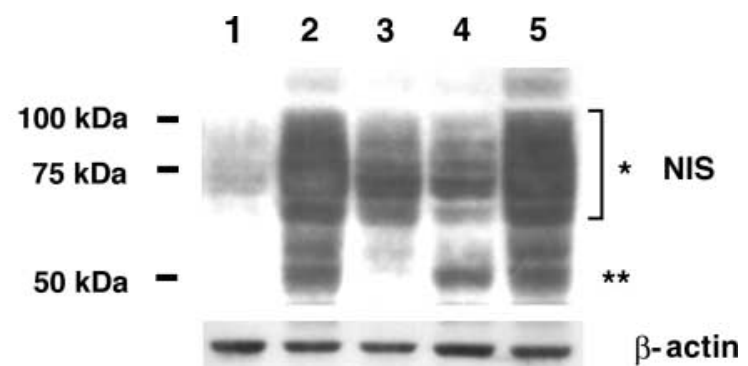

$\begin{array}{llllll}\text { LY294 } & (-) & (-) & (+) & (-) & (+)\end{array}$

FSK (-) $(+) \quad(+) \quad(+) \quad(+)$ actin

Ins $(-) \quad(-) \quad(-) \quad(+) \quad(+)$

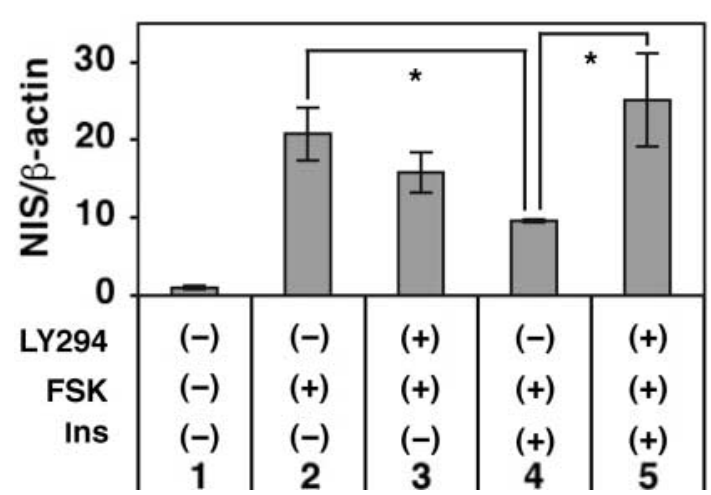

Figure 6 Effects of LY294002 on the NIS protein expression in FRTL-5 cells treated with or without insulin. Cells were maintained in the $5 \mathrm{H} 5 \%$ medium for 5 days, the $4 \mathrm{H} 0 \cdot 2 \%$ medium for 2 days, and then treated with $30 \mu \mathrm{M}$ LY294002 (LY294), $10 \mu \mathrm{M}$ of FSK, and/or $10 \mu \mathrm{g} / \mathrm{ml}$ bovine insulin (Ins) in the $4 \mathrm{HO} \cdot 2 \%$ medium for $48 \mathrm{~h}$. Whole cell lysates were prepared and western blot analysis was performed with anti-rat NIS antibody, as well as anti $\beta$-actin antibody. *glycosylated NIS; **non-glycosylated NIS. Lower panel. Quantitative analysis of the Western blotting of NIS. The broad bands of glycosylated NIS were quantitated and normalized with $\beta$-actin. The cells without FSK, insulin, or LY294002 were set at 1. Values are means \pm S.D. $(n=2) .{ }^{*} P<0 \cdot 01$.

expression in BHP 2-7 cells, the expression levels were still quite low, and reproducible quantitation was not obtained (data not shown).

NIS is regulated by TSH both at the transcriptional and posttranscriptional levels in rat thyroid cells (Ohno et al. 1999, Riedel et al. 2001, Taki et al. 2002). To investigate whether the PI3K inhibitor up-regulates NIS at the post-transcriptional level in thyroid cancer cells, we introduced a mammalian expression vector carrying human NIS cDNA (Saito et al. 1997) into BHP 2-7 cells, NPA cells, and ARO anaplastic thyroid cancer cells. The transient expression of NIS significantly increased iodide uptake in the tested cells $(\sim 5 \cdot 9$-fold, compared with background, in BHP 2-7 cells; 5.1-fold in NPA cells; and $\sim 13 \cdot 5-$ fold in ARO cells). LY294002 significantly enhanced the iodide uptake in BHP 2-7 cells (up to $3 \cdot 5$-fold; Fig. 7A), but not in NPA cells or ARO cells (data not shown). The effect in BHP 2-7 cells was concentration-dependent with an $\mathrm{EC}_{50}$ of $3.54 \mu \mathrm{M}$ (Fig. 7A). The specific inhibitor of $\mathrm{NIS}, \mathrm{KClO}_{4}$, abolished the
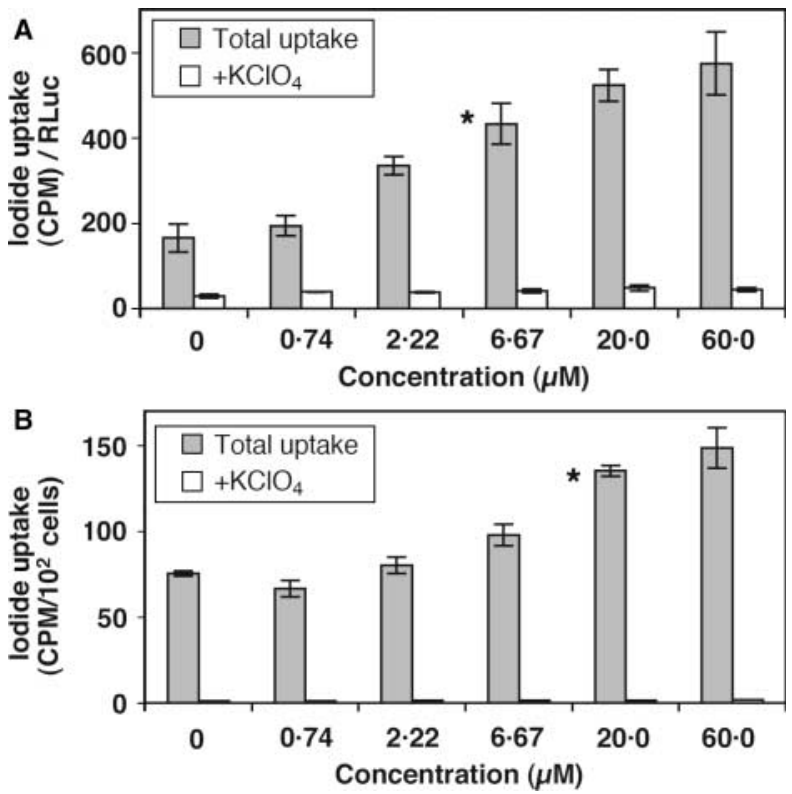

Figure 7 Effects of LY294002 on iodide uptake in BHP2-7 papillary thyroid cancer cells constitutively expressing NIS. (A). Cells were transiently transfected with pcDNA3-human NIS CDNA and pRLCMV and treated with the indicated concentration of LY294002 for $48 \mathrm{~h}$. lodide uptake assay and RLuc assay were performed with cell lysate after the incubation with ${ }^{125} \mathrm{I}(20 \mathrm{mCi} / \mathrm{mmol})$ and $10 \mu \mathrm{M} \mathrm{Nal}$ for $1 \mathrm{~h}$. The value of iodide uptake was normalized with the RLuc activity. (B) Cells, stably transfected with pcDNA3-human NIS cDNA by using G-418 as a selection marker, were pre-treated with the $5 \mathrm{H} 5 \%$ medium for 2 days, treated with the indicated concentration of LY294002 for $48 \mathrm{~h}$, and iodide uptake assay was performed. Values are expressed as means \pm s.D. $(n=3)$. ${ }^{*} P<0 \cdot 01$ when compared with the cells treated without LY294002.

iodide uptake induced by LY294002 (Fig. 7A), indicating that the induced uptake is mediated by NIS. Expression of RLuc, derived from co-transfected pRL-CMV vector, was not increased by LY294002 in the same batch. Since both exogenous NIS and $R L u c$ are controlled by the CMV promoter, the stimulatory effect of LY294002 is selective for the NIS expression, likely with the post-transcriptional regulation on the NIS mRNA.

To confirm the results in the transient expression studies, we established stable transfectant of NIS in BHP 2-7 cells with G-418 as a selection marker. The transfected cells expressed abundant iodide uptake $(66 \cdot 1$-fold, compared with background; Fig. 7B) after the selection with G-418, consistent with previous data (Kogai et al. 2001). LY294002 significantly enhanced the iodide uptake in those cells in a concentrationdependent manner with the $\mathrm{EC}_{50}$ of $8.52 \mu \mathrm{M}$ (Fig. 7B).

We further confirmed the effects of LY294002 on the NIS mRNA expression in the NIS-constitutively expressing BHP 2-7 cells. LY294002 $(30 \mu \mathrm{M})$ significantly increased the NIS mRNA expression in the serum-deprived cells (Fig. 8A). The effect was observed both with and without insulin (Fig. 8A), although the magnitude with insulin (3.71-fold) was slightly higher than that without insulin $(2 \cdot 63$-fold). A time course 

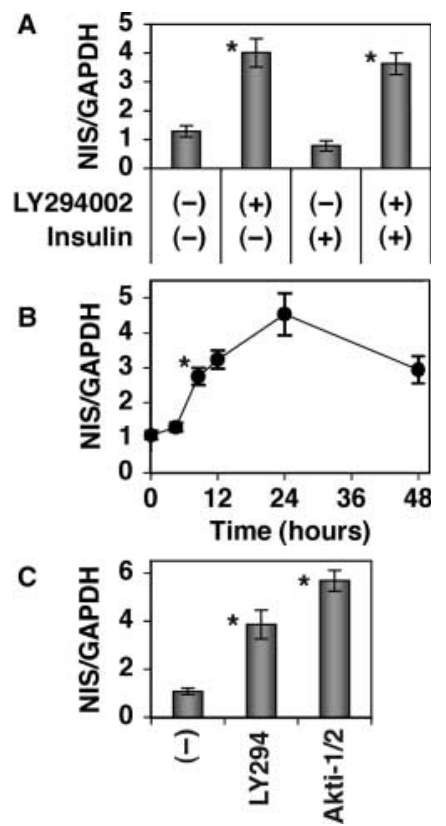

Figure 8 Effects of PI3K/Akt pathway inhibitors on the NIS mRNA expression in BHP 2-7 cells constitutively expressing NIS. (A) Induction of the NIS mRNA by LY294002 in NIS-stably transfected BHP 2-7 cells. Geneticin-selected cells, pre-treated with the $4 \mathrm{HO} \cdot 2 \%$ medium for 2 day, were treated with $30 \mu \mathrm{M}$ LY294002 and/or $10 \mu \mathrm{g} / \mathrm{ml}$ bovine insulin for $24 \mathrm{~h}$, and RT-qPCR of NIS was performed. (B) Time course of the NIS mRNA induction by LY294002 in NIS-stably transfected BHP cells. Cells, maintained with $10 \%$ fetal bovine serum, were treated with $30 \mu \mathrm{M}$ LY294002 for the indicated time. (C) Effects of an Akt inhibitor on the NIS mRNA expression in NIS-stably transfected BHP 2-7 cells. Cells, maintained with $10 \%$ fetal bovine serum, were treated with $30 \mu \mathrm{M}$ LY294002 (LY294) or $30 \mu \mathrm{M}$ Akti-1/2 for $24 \mathrm{~h}$, and RT-qPCR of NIS was performed. Since the expression of endogenous NIS was estimated more than 1000-fold less than that of the exogenous NIS (data not shown), the indicated values represent the exogenous NIS expression. Values are expressed as means \pm s.D. $(n=2-4)$.

${ }^{*} P<0 \cdot 01$, when compared with the cells treated without LY294002.

study indicated a more rapid induction of NIS mRNA within $8 \mathrm{~h}$ (Fig. 8B) than that of endogenous NIS induction in FRTL-5 cells (Fig. 2). The effect of LY294002 was not significantly inhibited by a translation inhibitor cycloheximide (data not shown), suggesting no requirement of de novo protein synthesis for the post-transcriptional induction of NIS.

The Akt1/Akt2 inhibitor, Akti-1/2 $(30 \mu \mathrm{M})$, mimicked the effect of LY294002 on the exogenous NIS expression in BHP 2-7 cells (Fig. 8C). Those data suggest that the inhibition of the PI3K/Akt pathway likely upregulates the NIS expression at the post-transcriptional level in Ret/PTC1-expressing papillary thyroid cancer cells.

\section{Discussion}

In this study, we demonstrated that inhibition of PI3K significantly induced iodide uptake, mediated by NIS, in rat thyroid cells, at the transcriptional and post-translational level. Stimulation of iodide uptake was also shown in papillary thyroid cancer cells with Ret/PTC1 expression engineered to constitutively express NIS, although the regulatory mechanism was distinct in those cells (summarized in Table 2). In rat thyroid cells, the induction of Nis mRNA after treatment with a PI3K inhibitor required insulin treatment and the stimulation of the cAMP pathway. Inhibition of the PI3K effector, Akt, did not influence Nis mRNA. Newly synthesized proteins, such as Pax8 and/or other protein(s), were required for the full induction of Nis. In contrast, the induction of iodide uptake did not require insulin treatment or the cAMP pathway stimulation. In the insulin-treated cells, the induction of iodide uptake is dependent on the upregulation of Nis mRNA and protein, while post-translational regulation is likely important in the insulin-deprived cells. PI3K inhibition also increased exogenous NIS expressed in Ret/PTC1-expressing papillary thyroid cancer cells. This post-transcriptional effect required Akt inhibition, but not the cAMP pathway stimulation, insulin, or newly synthesized protein.

Some differentiated thyroid cancer cells express abundant NIS mRNA and protein (Saito et al. 1998), but the radioiodide accumulation is reduced, likely due to the failure of NIS translocation to the plasma membrane (Dohan et al. 2001, Riesco-Eizaguirre et al. 2006). NIS can be regulated both at the transcriptional and post-translational levels in thyroid cells (Ohno et al. 1999, Riedel et al. 2001, Taki et al. 2002). In FRTL-5 cells, treatment with insulin and stimulation of cAMP pathway were both necessary for the induction of NIS mRNA and protein by LY294002, while the induction of iodide uptake did not require those treatments. LY294002 may increase the translocation of NIS to the plasma membrane in the absence of insulin or the cAMP stimulation. Posttranslational regulation of NIS by PI3K has also been proposed in breast cancer cells (Knostman et al. 2007).

TSH stimulates Nis expression at the transcriptional level through the NIS far-upstream enhancer, NUE (Ohno et al. 1999, Taki et al. 2002), and the proximal promoter (Endo et al. 1997, Ohmori et al. 1998) in rat thyroid cells. A paired

Table 2 Summary of conditions for NIS induction by LY294002

\begin{tabular}{|c|c|c|c|c|}
\hline & \multicolumn{2}{|l|}{ FRTL-5 } & \multicolumn{2}{|c|}{ NIS-expressing BHP 2-7 } \\
\hline & $\begin{array}{l}\text { Iodide } \\
\text { uptake }\end{array}$ & $\begin{array}{l}\text { NIS } \\
\text { mRNA }\end{array}$ & $\begin{array}{l}\text { lodide } \\
\text { uptake }\end{array}$ & NIS mRNA \\
\hline TSH treatment & No & $\mathrm{No}^{\mathrm{a}}$ & & \\
\hline Stimulation of $A C^{b}$ & No & Yes $^{a}$ & No & No \\
\hline Insulin treatment & No & Yes & No & No \\
\hline Inhibition of Akt & No & No & & Yes \\
\hline $\begin{array}{l}\text { De novo protein } \\
\text { synthesis }\end{array}$ & & Yes & & No \\
\hline
\end{tabular}

'Yes' in column indicates that the factor is required for the induction. ${ }^{a}$ Either FSK or TSH is required for the induction.

${ }^{\mathrm{b}} \mathrm{AC}$, adenylyl cyclase. 
box-containing transcription factor, $\mathrm{PAX} 8$, is required for the activation of the NUE (Taki et al. 2002). In FRTL-5 cells, LY294002 has been reported to target putative Nis regulatory sequence(s) between the proximal promoter and the NUE (Garcia \& Santisteban 2002), while PI3K inhibition stimulates the NUE through the upregulation of PAX8 in PCCL3 in other rat thyroid cells (Zaballos et al. 2008). Our RT-qPCR study indicated the significant induction of $\operatorname{Pax} 8$ mRNA in PCCL 3 cells, but not in FRTL-5 cells. The selective induction of PAX8 in PCCL3 cells may confer the higher NIS expression in those cells. Indeed, we observed a greater induction of $\mathrm{Nis}$ by LY294002 in PCCL3 cells, compared with FRTL-5 cells.

One of the TSH receptor signaling pathways, TSH receptor/G $\beta \gamma / \mathrm{PI} 3 \mathrm{~K}$, downregulates NIS expression in cAMP-independent manner in PCCL3 rat thyroid cells (Zaballos et al. 2008). Downregulation of G $\beta \gamma$, as well as PI3K inhibition, increases NIS expression through the upregulation of Pax8 binding to the NUE (Zaballos et al. 2008). LY294002 abolishes the inhibitory effect of G $\beta \gamma$ on the Pax8 binding to NUE, resulting in activation of the NUE in TSH-stimulated PCCL3 cells. Since FSK targets adenylyl cyclase, downstream of another $G$ protein, $G \alpha$, and does not stimulate the G $\beta \gamma$ production, the up-regulation of PAX8 binding has not been observed in FSK-stimulated PCCL3 cells (Zaballos et al. 2008). By contrast, our data with FRTL-5 cells indicated that the inhibition of PI3K induced Nis mRNA in both TSH and FSK stimulation. Pax 8 mRNA was induced by LY294002 in PCCL3 cells, but not in FRTL-5 cells. On the other hand, our experiments with a translation inhibitor cycloheximide in FRTL-5 cells indicate that another newly synthesized protein is required for the Nis induction by LY294002. The effects of PI3K inhibitor, therefore, are potentially mediated by at least two pathways, Pax8 dependent and independent. Since the induction of Nis mRNA by LY294002 in PCCL3 cells was significantly greater than that in FRTL-5 cells, activation of both pathways likely produces greater induction of Nis in PCCL3 cells.

Two broad-spectrum PI3K inhibitors, LY294002 and Wortmannin, but not a PI3KCA-selective inhibitor PI-103, significantly induced the iodide uptake in FRTL-5 cells. The present study and some previous reports (Garcia \& Santisteban 2002, Giuliani et al. 2007) indicated that these PI3K inhibitors, including PI-103, significantly induced the Nis mRNA expression. PI-103 likely inhibits the translation and/or post-translational regulation of NIS. Each inhibitor possibly has different 'off-target' effects, which may influence NIS expression at the different levels. A potent PI3K inhibitor, Quercetin, paradoxically reduces the Nis mRNA expression in FRTL-5 cells through inhibition of phospholipase- $\mathrm{A}_{2}$ pathway (Giuliani et al. 2007), although the NISinducing LY294002 is a derivative of Quercetin.

The effects of PI3K inhibitor on the endogenous NIS mRNA expression varied among tested cell lines. PCCL3 cells were the most sensitive cells, while papillary thyroid cancer cells, BHP 27 or NPA, did not significantly respond. Less response of NIS expression in thyroid cancer cells may be due to the reduced activity of NIS proximal promoter (Kogai et al. 2001), as well as epigenetic modifications of NIS (Venkataraman et al. 1999, Puppin et al. 2005). Our preliminary experiments with primary porcine thyroid cells indicated reduction of NIS mRNA by LY294002 in cells maintained with the 6H5\% medium (Kogai \& Brent, unpublished observation, 2008). The differential response among species is possibly dependent on the difference of regulatory sequence of NIS gene; the similarity of the $5^{\prime}$-flanking region (between NIS and the next gene Rpl18a) between rat (GenBank accession number NT_039500) and pig (CU463003) is only $7 \cdot 15 \%$.

Insulin, a major regulator of Akt, was not required for the exogenous NIS induction by LY294002 in Ret/PTC1expressing BHP 2-7 cells, although the induction was mimicked by pharmacological inhibition of Akt. Expression of Ret/PTC stimulates the PI3K/Akt pathway in thyroid cells even in the absence of insulin or serum (Miyagi et al. 2004). In Ret/PTC1expressing BHP 2-7 cells, the PI3K/Akt pathway may be still active, even without insulin or serum. A recent preliminary study has indicated that targeting of Akt in combination with MAPK inhibition significantly induced the NIS mRNA expression in several thyroid cancer cell lines (Hou et al. 2007).

The PI3K inhibitors have a potential to increase the radioiodide accumulation, as well as produce inhibitory effects on cell proliferation (Furuya et al. 2007), in some differentiated thyroid cancer tissue. Such inhibitors may promote uptake in some thyroid cancer metastases that are unresponsive to TSH stimulation, although these tumors may also be resistant to PI3K inhibition. High cumulative doses of radioiodine are associated with adverse effects, including infertility, salivary, and lacrimal gland dysfunction, and an increased risk of secondary cancer and leukemia (Schlumberger 1998). PI3K inhibition may permit effective treatment of thyroid cancer with lower dose of radioiodide. Variable selectivity of PI3K inhibitors was seen in cell lines as well as species differences. Further investigations with human cells and models are needed to optimize PI3K inhibition for NIS induction and iodide uptake in human thyroid tissues.

\section{Declaration of interest}

The authors declare that there is no conflict of interest that would prejudice the impartiality of this scientific work.

\section{Funding}

This study was supported by NIH RO1 CA089364 and VA merit review funds to $G A B$.

\section{Acknowledgements}

We would like to thank Carla Portulano and Dr Nancy Carrasco for providing anti-rat NIS antibody. We also thank Kenneth Marion and Drs Michael Fenton, Neil Tran, Chisato Tomoda, and Masahiro Sugawara for providing thyroid cells, and Dr Jerome Hershman for helpful discussions. 


\section{References}

Abramoff MD, Magelhaes PJ \& Ram SJ 2004 Image processing with Image. J Biophotonics International 11 36-42.

Dohan O, Baloch Z, Banrevi Z, Livolsi V \& Carrasco N 2001 Rapid communication: predominant intracellular overexpression of the $\mathrm{Na}(+) / \mathrm{I}(-)$ symporter (NIS) in a large sampling of thyroid cancer cases. Journal of Clinical Endocrinology and Metabolism 86 2697-2700.

El-Kholy W, Macdonald PE, Lin JH, Wang J, Fox JM, Light PE, Wang Q, Tsushima RG \& Wheeler MB 2003 The phosphatidylinositol 3-kinase inhibitor LY294002 potently blocks K(V) currents via a direct mechanism. FASEB Journal 17 720-722.

Endo T, Kaneshige M, Nakazato M, Ohmori M, Harii N \& Onaya T 1997 Thyroid transcription factor-1 activates the promoter activity of rat thyroid $\mathrm{Na}+/ \mathrm{I}-$ symporter gene. Molecular Endocrinology 11 1747-1755.

Furuya F, Lu C, Willingham MC \& Cheng SY 2007 Inhibition of phosphatidylinositol 3-kinase delays tumor progression and blocks metastatic spread in a mouse model of thyroid cancer. Carcinogenesis 28 2451-2458.

Garcia B \& Santisteban P 2002 PI3K is involved in the IGF-I inhibition of TSH-induced sodium/iodide symporter gene expression. Molecular Endocrinology 16 342-352.

Gharbi SI, Zvelebil MJ, Shuttleworth SJ, Hancox T, Saghir N, Timms JF \& Waterfield MD 2007 Exploring the specificity of the PI3K family inhibitor LY294002. Biochemical Journal 404 15-21.

Giuliani C, Noguchi Y, Harii N, Napolitano G, Tatone D, Bucci I, Piantelli M, Monaco F \& Kohn LD 2007 The flavonoid quercetin regulates growth and gene expression in rat Frtl-5 thyroid cells. Endocrinology 149 84-92.

Hou P, Liu D, Ji M \& Xing M 2007 Potent inhibition of thyroid cancer cells and reexpression of thyroid genes by dual knockdown of the PI3K/Akt and MAP kinase pathways. In American Thyroid Association, 78th Annual Meeting, pp S-105. New York.

Knight ZA, Gonzalez B, Feldman ME, Zunder ER, Goldenberg DD, Williams O, Loewith R, Stokoe D, Balla A, Toth B et al. 2006 A pharmacological map of the PI3-K family defines a role for $\mathrm{p} 110 \alpha$ in insulin signaling. Cell 125 733-747.

Knostman KA, McCubrey JA, Morrison CD, Zhang Z, Capen CC \& Jhiang SM 2007 PI3K activation is associated with intracellular sodium/iodide symporter protein expression in breast cancer. BMC Cancer 7137.

Kogai T, Endo T, Saito T, Miyazaki A, Kawaguchi A \& Onaya T 1997 Regulation by thyroid-stimulating hormone of sodium/iodide symporter gene expression and protein levels in FRTL-5 cells. Endocrinology 138 2227-2232.

Kogai T, Schultz JJ, Johnson LS, Huang M \& Brent GA 2000 Retinoic acid induces sodium/iodide symporter gene expression and radioiodide uptake in the MCF-7 breast cancer cell line. PNAS 97 8519-8524.

Kogai T, Hershman JM, Motomura K, Endo T, Onaya T \& Brent GA 2001 Differential regulation of the human sodium/iodide symporter gene promoter in papillary thyroid carcinoma cell lines and normal thyroid cells. Endocrinology 142 3369-3379.

Kogai T, Kanamoto Y, Li AI, Che LH, Ohashi E, Taki K, Chandraratna RA, Saito T \& Brent GA 2005 Differential regulation of sodium/iodide symporter (NIS) gene expression by nuclear receptor ligands in MCF-7 breast cancer cells. Endocrinology 146 3059-3069.

Kogai T, Taki K \& Brent GA 2006 Enhancement of sodium/iodide symporter expression in thyroid and breast cancer. Endocrine-Related Cancer 13 797-826.

Kogai T, Ohashi E, Jacobs MS, Sajid-Crockett S, Fisher ML, Kanamoto Y \& Brent GA 2008 Retinoic acid stimulation of the sodium/iodide symporter in MCF-7 breast cancer cells is meditated by the insulin growth factor-i/phosphatidylinositol 3-kinase and p38 mitogen-activated protein kinase signaling pathways. Journal of Clinical Endocrinology and Metabolism 93 1884-1892.

Kosugi S, Sasaki N, Hai N, Sugawa H, Aoki N, Shigemasa C, Mori T \& Yoshida A 1996 Establishment and characterization of a Chinese hamster ovary cell line, $\mathrm{CHO}-4 \mathrm{~J}$, stably expressing a number of $\mathrm{Na}+/ \mathrm{I}-$ symporters. Biochemical and Biophysical Research Communications 227 94-101.

Levy O, De la Vieja A, Ginter CS, Riedel C, Dai G \& Carrasco N 1998 N-linked glycosylation of the thyroid $\mathrm{Na}+/ \mathrm{I}-$ symporter (NIS). Implications for its secondary structure model. Journal of Biological Chemistry 273 22657-22663.
Miyagi E, Braga-Basaria M, Hardy E, Vasko V, Burman KD, Jhiang S, Saji M \& Ringel MD 2004 Chronic expression of RET/PTC 3 enhances basal and insulin-stimulated PI3 kinase/AKT signaling and increases IRS-2 expression in FRTL-5 thyroid cells. Molecular Carcinogenesis 41 98-107.

Ohmori M, Endo T, Harii N \& Onaya T 1998 A novel thyroid transcription factor is essential for thyrotropin-induced up-regulation of $\mathrm{Na}+/ \mathrm{I}-$ symporter gene expression. Molecular Endocrinology 12 727-736.

Ohno M, Zannini M, Levy O, Carrasco N \& di Lauro R 1999 The paired-domain transcription factor Pax 8 binds to the upstream enhancer of the rat sodium/iodide symporter gene and participates in both thyroid-specific and cyclic-AMPdependent transcription. Molecular and Cellular Biology 19 2051-2060.

Puppin C, D'Aurizio F, D’Elia AV, Cesaratto L, Tell G, Russo D, Filetti S, Ferretti E, Tosi E, Mattei T et al. 2005 Effects of histone acetylation on sodium iodide symporter promoter and expression of thyroid-specific transcription factors. Endocrinology 146 3967-3974.

Riedel C, Levy O \& Carrasco N 2001 Post-transcriptional regulation of the sodium/iodide symporter by thyrotropin. Journal of Biological Chemistry 276 21458-21463.

Riesco-Eizaguirre G, Gutierrez-Martinez P, Garcia-Cabezas MA, Nistal M \& Santisteban P 2006 The oncogene BRAF V600E is associated with a high risk of recurrence and less differentiated papillary thyroid carcinoma due to the impairment of $\mathrm{Na}+/ \mathrm{I}-$ targeting to the membrane. Endocrine-Related Cancer 13 257-269.

Saito T, Endo T, Kawaguchi A, Ikeda M, Nakazato M, Kogai T \& Onaya T 1997 Increased expression of the $\mathrm{Na}+/ \mathrm{I}-$ symporter in cultured human thyroid cells exposed to thyrotropin and in Graves' thyroid tissue. Journal of Clinical Endocrinology and Metabolism 82 3331-3336.

Saito T, Endo T, Kawaguchi A, Ikeda M, Katoh R, Kawaoi A, Muramatsu A \& Onaya T 1998 Increased expression of the sodium/iodide symporter in papillary thyroid carcinomas. Journal of Clinical Investigation 101 1296-1300.

Saji M \& Kohn LD 1991 Insulin and insulin-like growth factor-I inhibit thyrotropin-increased iodide transport in serum-depleted FRTL-5 rat thyroid cells: modulation of adenosine $3^{\prime}, 5^{\prime}$-monophosphate signal action. Endocrinology 128 1136-1143.

Schlumberger MJ 1998 Papillary and follicular thyroid carcinoma. New England Journal of Medicine 338 297-306.

Schmutzler C, Winzer R, Meissner-Weigl J \& Kohrle J 1997 Retinoic acid increases sodium/iodide symporter mRNA levels in human thyroid cancer cell lines and suppresses expression of functional symporter in nontransformed FRTL-5 rat thyroid cells. Biochemical and Biophysical Research Communications 240 832-838.

Shimura H, Haraguchi K, Miyazaki A, Endo T \& Onaya T 1997 Iodide uptake and experimental 131I therapy in transplanted undifferentiated thyroid cancer cells expressing the $\mathrm{Na}+/ \mathrm{I}-$ symporter gene. Endocrinology 138 4493-4496.

Taki K, Kogai T, Kanamoto Y, Hershman JM \& Brent GA 2002 A thyroidspecific far-upstream enhancer in the human sodium/iodide symporter gene requires Pax- 8 binding and cyclic adenosine $3^{\prime}, 5^{\prime}$-monophosphate response element-like sequence binding proteins for full activity and is differentially regulated in normal and thyroid cancer cells. Molecular Endocrinology 16 2266-2282.

Venkataraman GM, Yatin M, Marcinek R \& Ain KB 1999 Restoration of iodide uptake in dedifferentiated thyroid carcinoma: relationship to human $\mathrm{Na}+/ \mathrm{I}-$ symporter gene methylation status. Journal of Clinical Endocrinology and Metabolism 84 2449-2457.

Vitagliano D, Carlomagno F, Motti ML, Viglietto G, Nikiforov YE, Nikiforova MN, Hershman JM, Ryan AJ, Fusco A, Melillo RM et al. 2004 Regulation of p27Kip1 protein levels contributes to mitogenic effects of the RET/PTC kinase in thyroid carcinoma cells. Cancer Research 64 3823-3829.

Zaballos MA, Garcia B \& Santisteban P 2008 G $\beta \gamma$ dimers released in response to thyrotropin activate phosphoinositide 3-kinase and regulate gene expression in thyroid cells. Molecular Endocrinology 22 1183-1199.

Received in final form 15 July 2008

Accepted 19 August 2008

Made available online as an Accepted Preprint 1 September 2008 